\title{
DIASPORA ETNIK NON-ANGLO-SAXON \\ DALAM MASYARAKAT ETNIK ANGLO SAXON: KEGETIRAN DAN KETERASINGAN
}

\author{
Sugi Iswalono dan Niken Anggraeni \\ Fakultas Bahasa dan Seni Universitas Negeri Yogyakarta \\ email: sugi_iswalono@uny.ac.id
}

\begin{abstract}
Abstrak
Penelitian ini bertujuan untuk menemukan, memaparkan dan menganalisis: 1) jenis-jenis represi yang dialami para persona dalam puisi karya beberapa penyair Amerika yang berasal dari etnik non-Anglo-Saxon, yaitu Julia Alvarez, Naomi Shihab Nye, Rhina P. Espaillat, dan lê thi diễm thúy; 2) resistensi yang masingmasing persona lakukan atas represi yang mereka alami; dan 3) bagaimana akhirnya para persona tersebut menemukan jati diri mereka masing-masing sebagai akibat dari represi yang mereka alami dalam kehidupan sehari-hari mereka. Penelitian ini menggunakan pendekatan deskriptif kualitatif. Sumber data penelitian ini adalah puisi yang berjudul Bilingual Sestina karya Julia Alvarez, Blood karya Naomi Shihab Nye, Bilingual/Bilingile karya Rhina P. Espaillat, dan to my sister lê thi diem trinh shrapnel shards on blue water karya lê thi diễm thúy. Data diperoleh dengan teknik membaca dan mencatat karya-karya tersebut dan dianalisis dengan teori postkolonialisme dan sumber-sumber yang relevan. Hasil penelitian menunjukkan bahwa represi yang dialami oleh etnik minoritas ini sebagaimana direpresentasikan oleh persona dalam masing-masing puisi di atas terjadi dalam aspek kehidupan sosial-budaya, ekonomi, dan politik mereka, dan represi tersebut tidak hanya dilakukan oleh etnik mayoritas Anglo-Amerika, namun juga oleh kelompok mereka sendiri. Resistensi yang mereka lakukan pun terjadi dalam bidang yang sama. Jati diri yang mereka temukan berpijak pada resistensi yang mereka lakukan yang sebetulnya merupakan "counter attack" mereka.
\end{abstract}

Kata kunci: Anglo-Saxon/Amerika, postkolonialisme, represi, resistensi, temuan jati diri

\section{THE DIASPORA OF NON-ANGLO-SAXON ETHNICS IN THE ANGLO-SAXON ETHNIC COMMUNITY: BITTERNESS AND ALIENATION}

Abstract

This study aims at finding, describing, and analyzing: 1) types of repression experienced by the personae in some poems by American writers of non-Anglo-Saxon ethnic origins, i.e. Julia Alvarez, Naomi Shihab Nye, Rhina P. Espaillat, and lê thi diễm thúy; 2) the resistance against the repression they experience; and 3) how they 
come to their self-recognition on account of the repression which they bear in their everyday life. The study employed a qualitative descriptive approach. The data sources were poems entitled Bilingual Sestina by Julia Alvarez, Blood by Naomi Shihab Nye, Bilingual/Bilingile by Rhina P. Espaillat, and to my sister lê thi diem trinh shrapnel shards on blue water by lê thi diễm thúy. The data were collected by reading and making notes on the works and analyzed by the post-colonial theory and other related sources. The findings show that the repression experienced the ethnic minority as represented by the personae of the poems takes place in their socio-cultural, economic, and political aspects of life, and it is made not only by the ethnic majority of Anglo-Saxon, but also by their own groups. The resistance which they execute also takes place in the same aspects. As a matter of fact, their self-recognition is based upon the resistance they have brought about which is a sort of their counter attack.

Keywords: Anglo-Saxon/American, postcolonialism, repression, resistance, selfrecognition

\section{PENDAHULUAN}

Mengingat kata "English Poetry" tidak semata-mata hanya berarti puisi yang ditulis dalam bahasa Inggris, tetapi juga yang mempunyai muatan budaya Anglo-Saxon atau sering pula disebut Anglo-Celtic atau Anglo-American, atau bersinggungan, membicarakan, atau mempertentangkan budaya tersebut, atau dengan kata lain puisi yang ditulis oleh penutur asli bahasa Inggris (etnik Anglo-Saxon) atau pengguna bahasa Inggris yang bukan merupakan etnik Anglo-Saxon yang 'harus' menerima bahasa ini sebagai bahasa pertama mereka dalam interaksi dalam kehidupan mereka sehari-hari dengan diterimanya mereka sebagai merupakan warga negara dari negara-negara yang dikuasai oleh etnik Anglo-Saxon baik dalam artian budaya, sosial, ekonomi dan politik.

Wikipedia, The Princeton Review, dan Green akan menjadi acuan utama untuk lebih menjelaskan masalah yang cukup rumit ini. Wikipedia (2014:p.1) secara implisit mengatakan bahwa sastra Inggris merupakan karya sastra dalam bahasa Inggris yang dihasilkan oleh penulis tidak hanya dari England, tetapi juga dari Scotland, seluruh Ireland, Wales, dan juga mantan the British colonies. Definisi yang sepertinya mengulang apa yang sedikit telah disinggung di atas ini sekaligus mempertegas lagi dengan memasukkannya negara-negara mantan koloni Inggris (former British colonies), yang tentu saja meliputi Kanada, Amerika Serikat, Australia, New Zealand, dan Afrika Selatan. Hal ini dipertegas lagi oleh the Princeton Review (2014:p.2) yang mengatakan bahwa kajian sastra Inggris (English literature major) mencakup karya sastra yang dihasilkan oleh penulis dari "the British Isles and the British Commonwealth, from the very beginnings of the language we call English to the present day". Sementara itu, Green (1930:9) mengatakan bahwa sastra Australia bisa dianggap sebagai 'cabang dari sastra Inggris' (a branch of English literature). Meskipun pada akhirnya sastra Australia akhirnya menemukan ciri khasnya, menurut Green, pemahaman dan penilaian atas karya sastra Australia ini tidak bisa terlepas begitu 
saja dari induknya (the parent literature), yaitu sastra Inggris (English literature). Apabila sastra Australia bisa diterima sebagai bagian dari sastra Inggris, tentu saja sastra Amerika pun bisa diterima. Oleh karena itu, dengan sengaja, puisipuisi yang menjadi subyek penelitian ini dipilih empat puisi yang dihasilkan oleh penulis Amerika Serikat yang berasal dari etnis non Anglo-Saxon/American, yaitu (1) "Bilingual Sestina" oleh Julia Alvarez, (2) "Blood" oleh Naomi Shihab Nye, (3) "Bilingual/Bilingüe" oleh Rhina P. Espaillat, dan (4) "to my sister lê thi diem trinh shrapnel shards on blue water" oleh lê thi diễm thúy.

Bisa dikatakan bahwa puisi-puisi tersebut mewakili suara hati penyair immigrant non-Anglo-Saxon yang lain yang terpaksa harus mampu bertahan dari kungkungan represi dalam hampir semua aspek kehidupan yang dilakukan oleh pihak etnik mayoritas. Dengan kata lain, puisi-pusi tersebut merupakan ekspresi pengalaman / peristiwa hidup atau berkehidupan yang dialami oleh para emigran non Anglo-Saxon yang kemudian menetap atau menjadi warga negara dari "negara AngloSaxon". Anglo-Saxon inilah yang mewarnai negara Amerika Serikat dan, sementara itu, etnik-etnik minoritas akan termajinalkan dan harus menyesuaikan diri dengan segala apa pun dalam aktivitas kehidupan yang berbau Anglo-Saxon, baik dalam hal sosiobudaya, politik, dan ekonomi (Rudjito DA, 2010). Mereka harus menerima bahasa Inggris sebagai sarana komunikasi mereka dengan pihak lain meskipun kadang mereka merasakan bahwa bahasa Inggris yang harus mereka gunakan tidak bisa mengungkapkan isi hati mereka, kecuali dengan bahasa ibu mereka. Untuk sekedar mengurangi tekanan dan kungkungan tersebut, mereka diam-diam melakukan resitensi untuk tetap melestarikan nilai-nilai leluhur yang mereka yakini kebenarannya, yang akhirnya membawa mereka pada self-recognition.

Hal ini sesuai dengan apa yang disampaikan oleh Skerrett Jr. (2002) bahwa perjuangan kaum minoritas untuk mendapatkan self recognition ini tergambarkan dalam berbagai karya sastra yang mereka ciptakan. Menurut Skerrett melalui tulisan-tulisannya kaum minoritas ini berupa untuk memperbaiki citra negatif yang telah ditempelkan kepada mereka oleh "generations of outsiders."

Berdasarkan fokus penelitian yang disampaikan di atas, penelitian inti bertujuan untuk: (a) Bagaimana puisi-puisi tesebut secara eksplisit maupun implisit menyuarakan berbagai represi akibat kontak mereka dengan etnik mayoritas, dengan fokus pada represi dalam aspek sosio-budaya, politik, dan ekonomi yang sangat berkaitan status mereka sebagai warga negara minoritas, dan tentu saja, yang berkaitan pula dengan penerimaan pengguaan bahasa etnik mayoritas sebagai sarana komunikasi 'persona' dalam puisi-puisi tersebut; (b) bagaimana puisi-puisi tersebut mengungkapkan daya resistensi yang dilakukan para persona-nya atas hegemoni dalam bidang sosio-budaya, politik, dan ekonomi yang tidak bisa mereka hindari; dan (c) bagaimana pula puisipuisi tersebut memaparkan pembentukan persepsi tentang 'self dan 'others' karena perbedaan-perbedaan yang ada, yang akhirnya membawa mereka pada penemuan jati diri mereka. 
Teori yang yang akan digunakan dalam penelitian ini adalah Kajian Etnis yang merupakan bagian yang tidak terlepaskan dengan masalah poskolonialisme. Seperti dikatakan oleh Ryan (1999:147) bahwa pada akhir pertengahan abad ke 20, banyak negara-negara di kawasan Asia dan Afrika yang memperoleh kemerdekaannya dari negara penjajah mereka, terutama Inggris dan perancis. Dari sinilah mula terjadinya masalah etnis. Etnis Afrika yang tinggal secara terpencar di Amerika, misalnya, juga terpengaruh oleh masalah ini. Mereka berusaha keras untuk menghentikan segala macam praktek rasisme yang mereka alami selama bertahuntahun sebelumnya, dan ingin mendapatkan persamaan hak dengan etnik mayoritas yang menguasai peri kehidupan mereka, terutama, tentu saja, etnik Anglo-Saxon. Sementara itu setelah berakhirnya Perang Dunia II yang membuahkan kebrobrokan sektor ekonomi di negara-negara Eropa menyebabkan terjadinya migrasi dari Eropa ke Amerika dan Australia. Di samping ada faktor lain yang menyebabkan terjadinya migrasi ini, dan tidak hanya terjadi di Eropa, tetapi juga negara-negara Asia, yang banyak mengalami masalah politik dan perang saudara, seperti Irak, Afghanistan, dan Suriah. Orang-orang yang terdiri dari berbagai etnik ini terpaksa tinggal di negara-negara yang secara sosial-budaya di kuasai oleh etnik Anglo-Saxon. Dari sini pula terjadi masalah etnis: mereka mengalami hegemoni oleh kelompok etnis mayoritas dalam segala macam aspek kehidupan mereka. Dari aspek ini jelas bahwa masalah etnis tidak akan terlepas dari masalah poskolonialisme.
Buku yang menjadi rujukan atas teori ini adalah Literary Theory: A Practical Introduction yang diterbitkan pada tahun 1999 dan Teori Sastra: Sebuah Pengantar Praktis, diterjemahkan oleh Bethari Anissa Ismayasari terbit tahun 2011 yang keduanya merupakan karya Michael Ryan. Meskipun judul dan pengarang buku keduanya sama, versi bahasa Indonesia ini bukan merupakan terjemahan dari buku yang 1 disebut di sini. Kajian etnis dan poskolonial dibicarakan dalam satu bab yang tidak terpisahkan dalam buku yang disebut 1 di atas, dengan judul "Etnic, PostColonial, and International Studies" (hal. 147-55); dalam buku Ryan versi bahasa Indonesia kajian etnis dan kajian post-kolonial masing-masing dibicarakan dalam bab tersendiri. Hal ini tidak berarti bahwa buku veris bahasa Inggris kurang sempurna, tetapi justru buku tersebut tegas menunjukkan kaitan 2 kajian tersebut. Untuk memahami masalah peristilahan yang menjadi istilah khas teori ini, penelitian ini mengandalkan pada buku karya Bill Ashcroft, Gareth Griifiths, and Helen Tiffin yang berjudul Key Concepts in Post-Colonial Studies yang diterbitkan oleh Routledge (London) tahun 1998. Bila terdapat sumber-sumber referensi lain yang diacu dalam penelitian ini, sumber-sumber tersebut hanya akan menjadi pembanding atau penegas untuk memperjelas pembahasan teori.

Dalam penelitian ini, pembahasan akan diberikan pada bagaimana jati diri budaya etnis minoritas dimarjinalisasikan, atau bahkan dilenyapkan, oleh budaya etnis mayoritas. Jand (2004) menegaskan bahwa kata "culture" yang umumnya digunakan sebagai sinonim untuk istilah 'western culture' menunjuk- 
kan betapa selama ini budaya barat dianggap superior. Hal ini nampak pada penggunaan bahasa Inggris sebagai bahasa komunikasi yang harus mereka terima. Keharusan menerima bahasa Inggris ini merupakan represi yang etnik minoritas harus hadapi, disamping represi dalam bidang kesejahteraan sosial ekonomi seperti yang diungkapkan oleh lê thi diễm thúy. Dampak dari kungkungan ekonomi dan soaial budaya ini menimbulkan pula masalah marjinalisasi. Mereka menjadi terasing dalam lingkungan mereka sendiri. Oleh karena itu mereka hidup menjadi seorang 'outsider' dalam lingkungan sendiri, dan kemudian mereka berjuang dengan melakukan perlawanan yang bersifat resistensi untuk meraih self recognition.

\section{METODE}

Dengan demikian, fokus utama dari penelitian ini adalah pembeberan jenisjenis represi yang dialami dan resistensi yang dilakukan oleh etnik non AngloSaxon yang hidup di negara Amerika, dan bagaimana mereka merasa bahwa mereka telah sampai pada self recognition untuk menghilangkan atau sekedar mengurangi kegetiran hidup akibat kungkungan budaya, politik dan sosial-ekonomi oleh etnik mayaoritas. Hal ini akan sangat berarti bagi mereka agar mereka tetap dapat melangsungkan kehidupan mereka sehari-hari yang seoleh-oleh tetap menjalani kehidupan normal layaknya warga yang lain. Semua pengalaman hidup ini dikaji lewat puisi-puisi karya mereka seperti telah disebutkna di atas. Dengan demikian, data yang diperoleh berupa unit analitis berupa kata atau frase dari baris-baris dan bait-bait puisi yang merupakan ekspresi dari para penyair non AngloAmerika tersebut di atas yang membeberkan bagaimana mereka terhegomoni oleh kelompok etnis mayoritas AngloAmerika dalam bentuk represi dalam kehidupan mereka, dan bagaiman mereka akhirnya mencapai pengenalan jati diri mereka masing-masing sebagai akibat logis dari resistensi yang mereka lakukan atas represi tersebut.

Data dikumpulkan dengan cara pembacaan yang cermat sesuai dengan tujuan penelitian. Bersamaan dengan pembacaan cermat tersebut dilakukan pula pencatatan data yang kemudian dikategorikan. Tahap berikutnya adalah pemaknaan dan pendeskripsian data sesuai dengan masalah penelitian. Selain diperoleh dari pembacaan cermat atas puisi-puisi yang menjadi subyek penelitian ini, data juga diperoleh dari beberapa artikel pendukung yang berkaitan dengan kehidupan para penulis maupun kehidupan masyarakat non Anglo-Saxon yang hidup berwarga negara Amerika Serikat. Hal ini dilakukan dalam kerangka terori postkolonialisme, sehingga peneliti juga harus melakukan kajian terhadap kondisi masyarakat sosio-budaya, ekonomi, dan politik sebagaimana yang diekspresikan dalam keempat puisi yang menjadi subyek penelitian.

\section{HASIL DAN PEMBAHASAN}

Seperti telah diuraikan diatas bahwa penelitian ini difokuskan pada puisi karya penyair Amerika dari etnik non Anglo-Saxon. Berdasarkan pada penggunaan bahasa, tema, dan pengalaman yang disampaikan oleh para persona dalam puisi yang menjadi subyek penelitian ini, nampak jelas bahwa apa yang mereka sampaikan merupakan ekspresi 
pengalaman pribadi sang penyair, yaitu, Julia Alvarez, Naomi Shihab Nye, Rhina P. Espaillat, dan lê thi diễm thúy. Para persona tersebut, seperti para penyairnya, mengalami represi karena mereka dimarjinalkan dan dipaksa bisa menyesuaikan diri dengan lingkungan sosio-budaya tempat mereka tinggal. Demikian juga, dalam kehidupan politik dan ekonomi mereka, tentu saja oleh etnis mayoritas, yaitu Anglo-Saxon atau sering disebut pula Anglo-American.

Adanya hegemoni yang menimbulkan termarjinalisasinya etnik-etnik non Anglo-Saxon di Amerika bukan hal yang mustahil. Presiden Trump (Kendzior, 2016:p.1) pernah memposting ulang tentang white supremacist groups yang dianggap berbahaya karena bisa membuat Amerika kembali ke masa 200 tahun yang lalu, meskipun faktanya sejak tahun 1790, Amerika Serikat telah melakukan klasifikasi warga negaranya berdasarkan tiga ras, yaitu "free whites", "other free people", dan "slaves" (Kendzior, 2016:p.2). Karena pesatnya pertumbuhan etnik Hispanik (Latino), pada tahun 1980, etnik ini ditambahkan dalam klasifikasinya, dan, pada tahun 2010, Biro Sensus Amerika melakukan klasifikasi atas warga negaranya menjadi "White, Black or African American, American Indian or Alaska Native, Asian, Native Hawaiian or Other Pacific Islander, or Some Other Race" (Kendzior, 2016:p.3). Akhirnya, di kalangan rakyat Amerika, timbul klasifikasi berdasarkan berdasarkan ras, yaitu ras kulit putih, ras kulit hitam, dan ras Asia (Kendzior, 2016:p.6). Akibat lebih jauh dari kalsifikasi ini, menurut Kendzior (2016:pp.7-8), adalah terjadinya klasifikasi diantara ras kulit putih Amerika itu sendiri. Orangorang yang dulu tidak dianggap se- bagai ras kulit putih kemudian diterima sebagai ras kulit putih. Misalnya, orang-orang Irlandia yang sebetulnya termasuk ras kulit putih, tidak dianggap sebagai bagian dari ras kulit putih Amerika, meskipun kemudian "diterima" sebagai bagian dari ras kulit putih Amerika. Sebaliknya, orang-orang Italia, akhirnya tidak selalu diterima sebagai bagian dari ras kulit putih Amerika. Orang-orang Yahudi dimasukkan dalam kategori ras kulit putih, sementara itu, orang-orang Arab, yang sebetulnya termasuk ras kulit putih sebagaimana orang Yahudi, oleh sebagian besar rakyat Amerika dianggap bukan bagian dari ras kulit putih Amerika. Dengan demikian, "whiteness" di Amerika Serikat hanyalah merupakan "social construct" yang menguntungkan kelompok tertentu dan merugikan kelompok lain. Dalam hal ini, seperti ditegaskan Kendzior, orang-orang yang termasuk sebagai etnis kulit putih Anglo-Saxon menikmati keuntungan yang lebih besar dari pada etnis yang lain. Oleh karena itu tidak mengherankan apabila Julia Alvarez dan Rhina P. Espaillat yang berdarah Dominika yang termasuk di kawasan kepulauan Karibia, Naomi Shihab Nye yang berdarah Arab, dan lê thi diễm thúy yang berdarah Vietnam mengalami marjinalisasi dalam hampir semua aspek kehidupan mereka.

\section{"Bilingual Sestina" oleh Julia Alva- rez \\ Julia Alvarez dilahirkan pada tang- gal 27 Maret 1950 di New York, Ameri- ka Serikat. Namun ketika dia berumur tiga bulan, kedua orangtuanya yang merupakan imigran dari Republik Do- minika memutuskan untuk kembali ke negara asal mereka. Karena keterlibat-}


an ayahnya dalam gerakan politik yang gagal menjatuhkan diktator Rafael Trujillo pada tahun 1950an, mereka terpaksa kembali ke New York, Amerika ketika Julia Alvarez berumur 10 tahun. Meskipun dia harus berusaha keras beradaptasi terhadap lingkungan barunya di Amerika Serikat, Juila Alvarez berhasil lulus dari Middlebury College di Vermont pada tahun 1971, dan berhasil mendapatkan gelar master dalam bidang creative writing dari Syracuse University pada tahun 1975. Kemudian dia mendapat pekerjaan sebagai dosen sastra Inggris di Middlebury College. Pada tahun 1984, dia mulai menulis dan menerbitkan puisi dan karya sastra yang lain yang sebagian besar karya-karya tersebut berdasarkan pada pengalaman hidupnya sebagai orang Dominika yang tinggal di Amerika Serikat, dan puisi-puisi karya Alvarez sering disampaikan melalui perspektif seorang wanita ("Julia Alvarez", 2018:pp. $1 \& 10)$. Puisinya yang berjudul "Bilingual Sestina" menjadi salah satu subyek penelitian ini.

\section{Represi}

Persona dalam puisi ini mengalami represi dalam aspek sosio-budaya dalam kehidupannya sebagaimana dialami oleh Alvarez. Seperti yang diceriterakan dalam biografinya bahwa sebagai seorang siswa berdarah Latin yang menjadi kelompok minoritas di sekolah Katolik tempat dia belajar, Alvarez menghadapi diskriminasi karena darah Latin yang mengalir di tubuhnya, dan teman-teman sekolahnya sering memanggil dia "Spic!", ("Julia Alvarez, 2018:p.4), yaitu panggilan yang bersifat merendahkan bagi orang yang berasal dari negara yang berbahasa Spanyol. Dengan demikian dapat dikatakan bahwa apa yang disuarakan oleh persona puisi "Bilingual Sestina" merupakan suara Alvarez, dan persona puisi ini adalah juga Alvarez itu sendiri.

Secara tidak langsung represi yang persona alami disebabkan oleh sarana bahasa yang harus dia gunakan untuk berkomunikasi sehari-hari, yaitu bahasa Inggris, sementara itu, dia dibesarkan dalam masyarakat yang menggunakan bahasa Spanyol. Walaupun dia bisa melakukan komunikasi dengan masyarakat Amerika tempat dia tinggal, persona ini merasakan bahwa apa yang dikomunikasikan belum merupakan komunikasi dari lubuk hatinya. Dia lebih merasa nyaman jika dia harus berkomunikasi dalam bahasa ibu yang 1 dia pelajari ketika dia masih kanakkanak. Baris 1 dan 2 pada bait 1 ,

\section{Something I have to say ain't getting said \\ in this snowy, blond, blue-eyed, gum- chewing English...}

menunjukkan adanya represi ini. Persona merasa kesulitan dalam mengungkapkan apa yang ingin dia katakan dengan bahasa Inggris yang ironisnya merupakan cara agar dia dapat berkomunikasi dengan etnis mayoritas dalam komunitas tersebut. Hal ini juga diungkapkan lebih lanjut pada baris 6 , bait 2 dan baris 1 sampai 2 pada bait 3 ketika persona membandingkan bahasa dengan tanaman puteri malu, dan jin dalam botol dalam cerita Aladin, seperti yang ditulis dalam baris 4 sampai 6 dalam bait yang sama. Bait ini menyampaikan bahwa kosa kata da- 
lam bahasa yang berbeda kadang tidak memiliki makna yang sama

\section{... Language closed}

like the touch-sensitive morivivi whose leaves closed dan when we kids poked them, ...

\section{... How saying}

its name won't always summon up in Spanish or English

the full blown genie from the bottled nombre".

\section{Resistensi}

Resistensi persona atas represi atas dirinya adalah dengan tetap memelihara budaya dan bahasa Spanyol dalam dirinya. Hal ini dikarenakan, menurut persona, bahasa Spanyol lebih unggul daripada bahasa Inggris seperti yang digambarkan pada baris 3 , bait 6 . Sebagai bahasa ibu, bahasa Spanyol bagi persona lebih efektif dan tepat sasaran dibandingkan bahasa Inggris

--the world was simple and intact in Spanish--

Dibandingkan bahasa Inggris, bahasa Spanyol lebih mudah diucapkan

... as if the words were so close one left a mist of breath onthings saying

their names...

(baris 5--6, bait $6 \&$ baris 1, bait 7)

Secara personal, persona juga merasakan adanya kedekatan, kenyamanan, dan ikatan emosi dengan bahasa Spanyol seperti yang digambarkan pada baris 1 sampai 3 , bait 2 , ...--the sounds of Spanish

wash over me like warm island waters as I say

your soothing names

Disini jelas bahwa Alvarez menekankan pentingnya masa kanak-kanak yang membentuk jati diri seseorang meskipun kemudian dia tinggal di negara yang mempunyai budaya dan bahasa yang berbeda. Alvarez, seperti halnya persona dalam puisi karyanya ini, pertama kali bahasa yang dia pelajari adalah bahasa Spanyol, kemudian baru dia belajar bahsa Inggris. Dengan demikian, kosa kata bahasa Inggris yang dia pelajari hanyalah merupakan terjamahan dari kosa kata bahasa Spanyol yang telah dia kenal dengan baik. Dengan lain kata, bahasa dan budaya tempat dia berasal, yaitu Dominika, akan tertanam lebih dalam ingatannya.

... a child again learning the nombres of things you point to in the world before English

turned sol, tierra, cielo, luna to vocabulary words -

sun, earth, sky, moon. ....

Hal ini mengindikasikan bahwa budaya dan bahasa Spanyol masih kental membayangi dalam jiwanya meskipun ia kini tinggal di negara yang mayoritas penduduknya menggunakan bahasa Inggris.

\section{Penemuan Jati-Diri}

Dalam puisi ini, persona mengungkapkan identitasnya yang berbeda dengan kelompok mayoritas Anglo-Saxon di negara tersebut. Dalam hal ini, dia sadar akan budaya tempat dia berasal yang dirasakannya lewat penggunaan 
bahasa dalam kesehariannya. Sebagai imigran yang sehari-harinya harus bersosialisasi dengan kelompok mayoritas yang berbahasa Inggris, dia tetap tidak bisa begitu saja melupakan bahasa asalnya yaitu Spanyol, dan budaya yang mewarnai penggunaan bahasa tersebut. Bagaimana bahasa ibu dia, yaitu bahasa Spanyol, terasa lebih luwes dan pas baginya dari pada bahasa Inggris yang harus dia gunakan. Oleh karena tidak mengherankan kalau kemudian dia menghidupkan kembali bahasa ibu (Spanyol) dalam dirinya yang sempat dia tinggalkan saat dia harus belajar untuk menggunakan bahasa Ingggris. Secara alegoris hal ini diungkapkan dalam baris 2 sampai 4 , bait 4 ,

Open up again the house of slated windows closed

since childhood, where palabras left behind for English

stand dusty and awkward in neglected Spanish

Dengan demikian, jelas dia merasakan kembali pada jati dirinya sebagai warga yang berbeda dengan etnik mayoritas. Rasa tersebut kuat tertanam dalam dirinya sehingga meskipun dia berbicara dalam bahasa Inggris, dia tidak betul-betul bicara dalam bahasa Inggris sebab dalam hatinya dia berbicara dalam bahasa Spanyol, seperti yang tertuang pada dua baris-baris terkahir puisi ini,

... I now yearn for in Englishwords so close to what I mean that I almost hear my Spanish

heart beating, beating inside what I say en ingles.
Sementera itu, di awal puisi dia mengatakan bahwa secara fisik, dia berbeda dengan etnik Anglo-Saxon yang berambut pirang, bermata biru, dan gemar mengunyah permen karet.

\section{"Blood" oleh Naomi Shihab Nye}

Naomi Shihab Nye dilahirkan pada tahun 1952 di St. Louis, Missouri Amerika Serikat. Ayahnya adalah seorang Palestina yang berimigrasi ke Amerika karena perang Arab pada tahun 1948 yang membuat dia kehilangan segalagalanya. Ibunya adalah wanita Amerika berdarah Jerman dan Swiss. Nye ("Palestinian--American Poet Bridges Two Cultures" 2011:p.4) mengatakan bahwa perasaan diasingkan dan kerinduan selalu membayangi masa mudanya, dan dia berceritera pula tentang keterikatannya pada keadilan sosial. Oleh karena itu, dia selalu menentang penindasan dan kekerasan, dan setelah serangan udara atas the World Trade Center pada tahun 2001, dia sangat aktif menyuarakan hati nurani etnis Amerika-Arab, menentang terorisme, dan perasaan prejudis bangsa Amerika terhadap bangsa Arab ("Naomi Shihab Nye", 2018:p.7).

Nye banyak meluangkan masa mudanya di Jerusalem dan San Antonio, Texas. Ketertarikannya dpada puisi muncul sejak Nye masih kanak-kanak ketika dia melihat penampilan penyair Amerika Carl Sandburg di TV, dan mendengarkan puisi yang dibacakan oleh ibunya. Dia memperoleh gelar BA dalam bidang sastra Inggris dan agamaagama dunia di Trinity University.

Sebagian besar karya-karya puisinya berdasarkan pada pengalaman pergaulan hidupnya dengan orang-orang dan sanak saudara dia yang dia kenal 
dengan baik ("Biography", 2018:p.2). Nye sendiri mengakui bahwa karyakarya yang dia hasilkan merupakan suara-suara dari orang-orang di sekeliling kehidupanya ("Naomi Shihab Nye", 2018:p.3). Selain membicarakan tentang apa yang terjadi pada diri dan keluarganya ketika dia masih kanakkanak, dalam puisinya yang berjudul "Blood", Nye membicarakan pula tentang konflik yang terjadi antara rakyat Palestina dan Israel.

\section{Represi}

Dalam puisinya yang berjudul "Blood", Nye menggambarkan adanya represi pada diri persona yang dia gunakan untuk menyuarakan hati-nuraninya dalam aspek politik dalam bentuk sentimen etnis. Etnis Anglo-Saxon/ Amerika yang merupakan etnis mayoritas bertindak rasis terhadap etnis Arab/ Palestina yang tinggal di negara tersebut. Rasisme ini bukan hanya masalah personal namun merupakan masalah publik yang menyangkut seluruh etnis imigran Arab di negara tersebut. Represi ini ditunjukkan pada dua baris awal di bait 3 ,

\section{Years before, a girl knocked, wanted to see the Arab}

Kedua baris ini menggambarkan sikap rasis masyarakat Amerika terhadap etnis minoritas Arab. Ketidak tahuan dan rasa penarasan memacu seorang anak untuk melihat seperti apakah penampakan fisik etnis Arab. Tindakan yang tanpa dia sadari merupakan rasisme ini nyatanya telah menjadi hal yang wajar dilakukan oleh warga Amerika pada saat itu karena minimnya pemahaman mereka terhadap bangsa Arab.
Lebih jauh lagi, sikap rasisme ini dipertontonkan secara lebih terbuka dan luas lewat media cetak. Dengan memanfaatkan gaya bahasa personifikasi, Nye menggambarkan bahwa masalah rasisme ini merupakan masalah umum yang menyangkut tidak hanya seluruh etnis Arab di Amerika, namun bangsa Arab pada umunya, sebagaimana diperlihatkan pada headline surat kabar waktu itu. Dia mengatakan betapa headline tersebut mampu membekukan darah yang mengalir dalam dirinya. Pada headline tersebut terdapat foto sorang anak Palestina kecil yang masih belum tahu apa yang terjadi pada bangsanya harus ikut menanggung akibat perang yang seperti tidak akan pernah berakhir dengan kehilangan tempat tinggalnya.

Today the headline clot in my blood.

A little Palestinian dangles a truck on the front page.

Homeless fig,

(baris 16 sampai 18 , bait 4)

Selain menggunakan personifikasi seperti yang nampak pada baris $1 \mathrm{ku}-$ tipan diatas, Nye juga menggunakan symbol, "fig", pohon zaitun, yang merupakan symbol kedamaian. Dengan demikian, anak kecil tersebut dianggap anak yang jiwanya masih 'damai', belum mengerti kotornya dunia ini karena ulah manusia yang menghuninya.

\section{Resistensi}

Resistensi kelompok minoritas Amerika-Arab atas represi etnis Anglo-Saxon disuarakan oleh Nye melalui rasa kebanggan yang tertanam dalam diri etnis Amerika-Arab karena adanya garis keturunan Arab yang mengalir dalam darahnya. Bait 1 dan 2, serta 
baris 4 sampai 8 pada bait 3 dari puisi ini menggambarkan kebanggaan sang ayah dari persona ciptaan Nye yang merupakan etnis Arab murni. Dia menunjukkan bahwa orang Arab lebih hebat, lebih religius, lebih beradab serta memiliki banyak kearifan lokal. Di bait 1 sang ayah menunjukkan betapa terampilnya orang Arab yang mampu menangkap lalat dengan tangan kosong, dan hal tersebut tidak akan dapat dilakukan oleh orang lain, termasuk orang Amerika,

"A true Arab knows how to catch a fly in his hands,"

my father would say. And he'd prove it, cupping the buzzer instantly

while the host with the swatter stared.

Bait 2 menggambarkan kehebatan, kearifan local, dan nilai relijiusitas yang lebih yang dimiliki orang Arab. Dia tunjukkan kehebatan tersebut dengan menceriterakan bagaimana ketrampilan yang dimiliki orang Arab tidak akan pudar tetapi akan tetap tumbuh berkembang. Dengan menggunakan gaya bahasa sinekdoki, 'telapak tangan' yang dikatakan mampu menangkap lalat yang sedang terbang, Nye mengacu pada ketrampilan yang dimiliki orang Arab. Gaya bahasa simile yang membandingkan ular dan tangan orang Arab, dia menceriterakan bagaimana ketrampilan yang dimiliki orang Arab tersebut tidak akan pernah pudar, sebagaimana ular yang menjadi muda kembali setelah berganti kulit, sementara itu, gaya bahasa metafora yang terdapat dalam ekspresi 'in the spring' yang menggambarkan waktu tumbuh kembangnya tanaman digunakan untuk menggambarkan ketrampilan tersebut yang bahkan akan lebih menghebat.

Kearifan lokal bangsa Arab ditunjukkan pada baris 6 , yang menyatakan bahwa mereka mampu mengobati kulit tangan yang mengelupas dengan menggunakan bahan alami yaitu semangka. Sisi relijius yang mereka miliki ditunjukkan dalam hal pemeberian nama kepada anak-anak mereka, seperti nama 'Shihab' memiliki arti 'shooting star', bintang beralih, yang mengandung arti kebaikan.

In the spring our palms peeled like snakes.

True Arabs believed watermelon could heal fifty ways.

After that, my father told me who he was,

"Shihab"- "shooting star"-

a good name, borrowed from the sky.

Once I said, "When we die, we give it back?"

He said that's what a true Arab would say.

Kebanggan atas apa yang dimiliki oleh orang Arab ini akan menimbulkan kebanggaan pula pada diri etnis Arab yang tinggal di Amerika Serikat.

\section{Penemuan Jati-Diri}

Pada awalnya, persona dalam puisi ini belum mengetahui identitasnya yang berdarah campuran Arab-Amerika. Hal ini digambarkan pada baris 8 sampai 11 pada bait 3 , saat seorang anak ingin melihat bagaimana wujud orang dari kelompok etnis Arab. Jawaban yang diberikan oleh persona dalam puisi ini menunjukkan ketidak tahuan dia tentang jati dirinya dan keluarganya. 
Years before, a girl knocked, wanted to see the Arab.

I said we didn't have one.

After that, my father told me who he was,

Setelah dia mengetahui identitasnya yang sebenarnya, dia mempertanyakan posisi mana yang harus diambilnya ketika masalah rasisme tersebut semakin parah "What flag can we wave?" (baris 4 , bait 4). Ketika permasalahan rasisme semakin parah, persona ini mengkritik sikap masyarakat Amerika tersebut. Pada dua baris terakhir di bait keempat dia menggambarkan penderitaan etnis Arab atas sikap rasis masyarakat Amerika. Secara simbolik dan metaforik, dia mengatakan "I wave the flag of stone and seed, / table mat stitched in blue" (baris 5-6, bait 4) yang bermakna kurang lebih adalah bahwa etnis Arab merupakan orang biasa seperti yang lainnya yang juga sama bergunanya seperti etnis lain, namun mereka kini terpenjara dalam kesedihan atas tragedi yang menimpa mereka.

Dalam frustasinya, dia mengkritik orang Amerika yang mengaku beradab namun ironisnya justru berperilaku tidak beradab, seperti nampak pada baris 4-6, bait 5, "I drive into the country to find sheep, cows, I to plead with the air: / Who calls anyone civilized?" Atas alasan tersebut, dia kemudian memilih untuk membela etnis Arab seperti yang digambarkan pada lima baris terakhir bait 5 . Dengan demikian, persona yang merupakan suara jiwa Nye ini telah menemukan jati dirinya.
"Bilingual/ Bilingüe" oleh Rhina P. Espaillat

Rhina P. Espaillat dilahirkan pada tahun 1932 di Santo Domingo, Republik Dominika dari keluarga terhormat di Dominika. Setelah salah satu anggota keluarga besarnya menentang Presiden Rafael Trujillo yang saat itu berkuasa, keluarga Espaillat terpaksa mengasingkan diri dengan berimigrasi ke Amerika Serikat pada tahun 1939. Dia memperoleh gelar B.A. dari Hunter college pada tahun 1953, dan menyelesaikan jenjang sarjananya di Queens College pada tahun 1964. Kemudian, dia menjadi guru sastra Inggris, dan setelah pension, dia menjadi tokoh kunci dari para penyair New Formalist yang dikenal sebagai Powow River Poets ("Rhina Espaillat", 2018:p.2).

Sejak muda, Espaillat sudah menulis puisi, mula-mula dalam bahasa Spanyol, kemudian baru dalam bahasa Inggris. Karya Robert Frost dan Richard Wilbur, dia terjemahkan dalam bahasa Spanyol, dan sebaliknya, dia menerjemahkan puisi karya St. John of the Cross dari bahasa Spanyol kedalam bahasa Inggris (Rhina Espaillat, 2018:p.5). Puisi-puisi karya Espaillat menyuarakan pengalaman hidup yang segar dan tidak menunjukkan keterikatan pada aturan penulisan yang kaku (Rhina P. Espaillat, 2018:p.3). Puisinya yang berjudul "Bilingual/ Bilingüe", yang menjadi salah satu subyek penelitian ini, menceriterakan tentang permasalahan jiwa persona karena harus hidup dalam dua bahasa, dan oleh karena itu, dia pun harus hidup dalam dua dunia, seperti apa yang dialami oleh Espaillat. 


\section{Represi}

Puisi yang berjudul "Bilingual/Bilingüe" karya Rhina P. Espaillat ini secara eksplisit menggambarkan represi yang terjadi pada diri persona karena masalah penggunaan bahasa. Namun represi tersebut justru datang dari pihak keluarga persona sendiri yang merupakan etnis Hispanik di Amerika. Espaillat sendiri ("Intro to Poetry: Bilingual/ Bilingue", 2011:p.1) mengakui bahwa ayahnya melarang dia menggunakan bahasa Inggris dan Spanyol sekaligus di dalam rumah. Ayah Espaillat menginginkan penggunaan kedua bahasa tersebut secara terpisah: bahasa Inggris harus digunakan di luar rumah, di dalam rumah harus menggunakan bahasa Spanyol. Upaya Espaillat untuk tetap bisa hidup tegar diantara dua dunia ini dia ekspresikan ke dalam puisi yang menjadi kajian penelitian ini. Hal ini jelas terlihat pada apa yang terjadi pada persona yang dia ciptakan yang mengalami hal yang sama dari ayahnya,

My father liked them separate, one there, one here (allá y aqui), ...

(baris 1-2, bait 1)

"English outside this door, Spanish inside," he said, "y basta." ...

(baris 1-2, bait 4)

Ayah dari persona puisi ini pun melakukan hal yang sama, melarang persona menggunakan bahasa Inggris di dalam rumah dan mewajibkan penggunaan bahasa Spanyol di rumah. Ruparupanya si ayah sadar bahwa sebagai imigran dari kelompok minoritas, mereka harus menggunakan bahasa Inggris agar dapat diterima oleh kelompok mayoritas, namun demikian dia khawatir anaknya justru akan melupakan jati dirinya dan menjadi seperti orang Amerika. Dia tidak ingin anaknya melupakan siapa mereka di masa lalu mereka. Justru dia menginginkan agar anaknya selalu mengingat dari mana asal usul mereka, seperti nampak pada baris 1 , bait 2 , dan baris 1 bait 3 "as if aware that words might cut in two his daughter's heart", dan to what he was-his memory, his name". Sadar atau tidak sadar keinginan ayah persona merupakan represi yang akhirnya menimbulkan gangguan psikologis pada diri persona.

\section{Resistensi}

Bentuk resistensi persona atas represi penggunaan bahasa tersebut adalah menolak pembatasan bahasa yang dia pelajari. Dia ingin menggunakan kedua bahasa tersebut untuk memahami dunia. Sejak kecil, dia sudah berusaha keras untuk tetap bisa hidup diantara dua dunia tersebut.
..." But who can divide
the world, the word (mundo y palabra) from
any child? I knew how to be dumb
(baris 2 , bait $4 \&$ baris $1-2$, bait 5 )

Perlawanan keras yang di tunjukkan kepada ayahnya adalah ketika dia menolak larangan ayahnya tersebut dengan cara dia terus belajar menggunakan bahasa Inggris tanpa sepengetahuan ayahnya sehingga dia bisa berbahasa Inggris jauh lebih baik daripada ayahnya, meskipun di depan ayahnya dia tidak menggunakan bahasa Inggris.

and stubborn (testaruda); late, in bed, I hoarded secret syllables I read 
until my tongue (mi lengua) learned to run

where his stumbled.

(baris 1-2, bait $6 \&$ baris 1-2, bait 7)

dan terus belajar menggunakan bahasa Inggris tanpa sepengetahuan ayahnya hingga ia bisa berbahasa Inggris jauh lebih baik daripada ayahnya seperti yang digambarkan pada,

Untuk menjawab kekhawatiran sang ayah, si anak mengklaim bahwa jati diri Spanyol masih ada dalam dirinya "and still the heart was one". Sebagai buktinya, ia menyisipkan kosa kata Spanyol dalam bahasa Inggrisnya.

\section{Penemuan Jati-Diri}

Sebagai imigran, persona, sebagaimana Espaillat, dibawa ayahnya untuk hidup di negara baru dengan bahasa yang baru pula, dalam hal ini bahasa Inggris. Bahasa Spanyol yang digunakan dalam puisi ini digunakan justru untuk menunjukkan dan menguatkan represi macam apa yang dialami oleh persona.

Dalam baris 2 pada bait 3, kata ' $k e y$ ' merupakan metafora yang Espaillat gunakan untuk menunjukkan bahwa si ayah tidak mungkin bisa 'mengunci' anaknya di dalam rumah untuk tetap menggunakan bahasa Spanyol, dan membuka pintu rumah agar anak bisa menggunakan bahasa Inggrisnya (baris 1 pada bait 4).

.... with a key he could not claim.

"English outside this door, Spanish inside,"

Hal ini menunjukkan keinginan si anak bahwa ayahnya seharusnya sadar dengan apa yang terjadi sejak mereka tinggal di negara baru. Bagaimana pun juga mereka tidak akan bisa lepas dari realita yang mereka hadapi. Mereka tinggal di Amerika, mereka harus menerima bahasa Inggris atau mereka akan lebih terpinggirkan.

Berbeda dengan ayahnya, si anak yang sadar akan keadaan yang mereka hadapi ini mulai menemukan jati dirinya. Meskipun dia harus hidup dengan dua bahasa yang berbeda sekaligus, dan dalam budaya yang terbelah, hatinya tetap satu, dan tidak mungkin terbelah dua, "... And still the heart was one." (baris 2, bait 7). Dengan demikian, dapat disimpulkan bahwa kedua bahasa tersebut sama pentingnya bagi persona, sebagaimana Espaillat yang akhirnya menjadi penyair terkemuka di Amerika karena kemampuannya menulis puisi dalam dua bahasa. Misalnya adalah puisi "Bilingual/Bilingüe" yang menjadi subyek penelitian ini.

\section{"To my sister lê thi diem trinh shrap- nel shards on blue water" oleh lê thị diễm thúy}

Dibandingkan dengan ketiga penyair yang telah dibahas di atas, referensi tentang lê sangat terbatas. Namun, informasi yang disampaikan di sini diharapkan cukup mampu untuk memberikan latar belakang kehidupan lê, penyair, novelis, dan artis panggung Amerika-Vietnam yang dilahirkan di Phan Thiêt, Vietnam Selatan (waktu itu Vietnam terbagi dua: Utara dan Selatan), pada tahun 1972 ketika sedang berlangsung Perang Saudara di Vietnam. Pada tahun 1978, lê bersama ayahnya melarikan diri dari Vietnam dengan menggunakan kapal nelayan, yang kemudian ditolong oleh Angka- 
tan Laut Amerika dan ditempatkan di kamp pengungsi di Singapura sebelum akhirnya ditempatkan di Kalifornia Selatan. Dua tahun kemudian, ibunya dan saudara perempuannya bergabung dengannya. Dia mempunyai enam saudara, dua diantaranya meninggal tenggelam, dan dua saudara dilahirkan di Amerika.

Pada tahun 1990, lê pindah ke Massachussetts untuk belajar cultural studies dan post-colonial literature di Hampshire College. Dia mulai menulis karya sastra setelah berhasil menamatkan belajarnya di kampus tersebut. Pada tahun 1998, bersama ibunya, lê pulang ke kampong halamannya di Vietnam. Kepulangannya ini memberikan kesan yang mendalam pada dirinya, betapa beratnya penderitaan hidup yang harus kedua orang tuanya jalani ketika mereka tinggal di Amerika. Pada tahun 2001, ibunya pulang ke Vietnam, dan meninggal dunia karena kanker. Ayahnya menyusul ke Vietnam pada tahun 2003.

\section{Represi}

Represi yang digambarkan dalam puisi lê yang berjudul "to my sister lê thi diem trinh shrapnel shards on blue water" adalah represi dalam aspek ekonomi yang dialami etnis Vietnam di Amerika. Persona yang merupakan pelarian perang Vietnam merasa tidak mendapatkan kesejahteraan ekonomi. $\mathrm{Hal}$ ini digambarkan pada bait 2 dan 3 , yang dalam bait ini persona membandingkan kehidupannya di masa lalu di Vietnam yang mudah dan aman dengan kehidupannya sekarang yang sulit ketika dia berada di Amerika, seperti digambarkan pada baris 1 sampai 8 , bait 2 , ma took the train every morning

sunrise

from phan thiet to saigon

she arrived

carrying food to sell at the markets

past sunset

late every evening she carried her empty

baskets

home

Baris-baris pada bait 2 ini menggambarkan lancarnya si ibu dalam mendapatkan nafkah, legal, dan penuh harapan. Kenyataan tersebut berbanding terbalik dengan apa yang dia alamai di Amerika.
once ba bought an inflatable raft
yellow and black
he pushed it out onto a restricted part of water
in southern california
after midnight
to catch fish in the dark
it crashed against the rocks
he dragged it back to the van
small and wet

Bait di atas menunjukkan betapa sulitnya kehidupan mereka dalam keseharian. Hanya sekedar untuk menyambung hidup, mereka terpaksa harus menanggung malu denga melakukan tindakan illegal dengan hasil yang tidak sebarapa banyak, 'mencari ikan di laut terlarang'. Disini jelas bahwa apa yang mereka lakukan adalah keterpaksaan. Secara implicit, jelas pula bahwa mereka tidak mendapatkan pekerjaan layak sebagaimana warga negara lainnya. Secara ekonomis, mereka terpinggirkan. Dengan mata pencaharian seperti itu, dapat dibayangkan betapa beratnya be- 
ban ekonomi yang harus mereka tanggung dalam kesehariannya.

Secara alegoris, ketidak nyamanan kehidupan mereka digambarkan pada baris 2 dan 3 pada bait 5 , "we have lived our lives/ on the edge of oceans". Secara harafiah, mereka tinggal di dekat laut, mengingat mata pencaharian utama mereka mencari ikan. Namun, ungkapan 'on the edge of oceans' menyiratkan pula bahwa kehidupan mereka tidak nyaman, mengandung resiko, sebagaimana rumah yang berada di bibir pantai yang sewaktu-waktu bisa tergulung ombak. Oleh karena itu, secara alegoris pula, persona ciptaan lê dalam puisi ini merindukan untuk bisa pulang ke kampung halamannya di Vietnam.

\section{in anticipation of}

sailing into the sunrise

(baris $5 \& 6$, bait 5)

Layaknya nelayan yang berlayar pulang ke daratan di pagi hari dengan harapan besar dapat menafkahi keluarganya dengan hasil yang dipeolah, persona ini pun ingin kembali ke tanah airnya dengan harapan bisa mendapat kehidupan yang lebih baik. Kata 'the sunrise' dalam baris diatas menyiratkan sebuah harapan. 'sunrise' memberikan penerangan, cahaya, dan kehangatan, dan pada waktu ini semua orang mulai melakukan aktifitas mereka. Kehidupan dimulai dari pagi hari saat matahari mulai terbit. Bahkan candi-candi uatama di Jawa, seperti Candi Borobudur dan Prambanan, mempunyai pintu utama menghadap ke timur, ke arah matahari terbit, karena pagi hari menyimbolkan kehidupan yang penuh harapan.

\section{Resistensi}

Bentuk resistensi persona atas represi tersebut adalah dengan menyuarakan bahwa Vietnam bukanlah seperti yang orang Amerika pikir: medan perang. Apa yang terjadi sebenarnya adalah perangnya Blok Timur yang dikomandani Uni Sovyet (pada waktu itu) melawan Blok Barat yang dikomandani Amerika Serikat, yang mengganggu masalah politik dan ideologi di kedua Vietnam, dan secara pribadi membuat kehidupan persona dalam puisi ini, sebagimana halnya dengan lê, terluntalunta.

Dia mengingatkan bahwa di Vietnam juga ada kehidupan normal, keluarga, saudara, cinta dan 'dunia' yang tidak seharusnya tertutupi oleh kekejaman perang. Di Vietnam tidak ada rasa ketakutan. Dia tidak ingin mereka yang merupakan imigran atau pelarian perang tersebut terlupakan begitu saja tanpa ada yang peduli. Persona juga mengkritik ketidakpedulian etnis mayoritas Amerika yang menjadi bibit kepedihan kehidupan yang persona alami. Semua ini dia ungkapkan di bait 6, 7 dan 8.
$i$ tell you all this
to tear apart the silence
of our days and nights here
$i$ tell you all this
to fill the void of absence
in our history here

we are fragmented shards

blown here by a war no one wants to remember

in a foreign land

with an achingly familiar wound 
vietnam is not

a word

a world

a love

a family

a fear

to bury

Pada bait ke 8 , luka psikologis yang dialaminya akibat perang Vietnam dan masih ditambah lagi dengan tidak adanya kesejehteraan ekonomi bagi mereka memotivasi persona untuk menyuarakan bahwa Vietnam bukanlah suatu ancaman ataupun perang untuk ditakuti, bahwa Vietnam adalah hal yang nyata yang tidak seharusnya dilupakan. Sebagai klimaksnya, persona menegaskan bahwa Vietnam bukanlah suatu neraka peperangan, "let people know /VIETNAM IS NOT A WAR" (bait 9) yang sebagai penegasannya dia ulang sebanyak tiga kali dengan menggunkan huruf besar, melainkan kedamaian dan persaudaraan yang tidak seharusnya dimanfaatkan untuk kepentingan pihak luar.

\section{but a piece \\ of \\ us, \\ sister}

(baris 3-6, bait 11)

Dengan keyakinan bahwa Vietnam adalah bumi damai baginya, dan karena tekanan ekonomi yang dia dan keluarganya alami selama tinggal di Amerika, tidak mengherankan kalau dia ingin pulang ke tanah leluhurnya yang penuh harapan ini, sebagimana telah dibicarakan diatas.

\section{Penemuan Jati-Diri}

Persona dalam puisi ini merupakan imigran/ pelarian perang Vietnam yang sepenuhnya sadar akan keadaan dirinya dan kehidupannya, dan berharap orang Amerika berhenti memandang Vietnam sebagai medan perang. Dia menekankan hal tersebut dengan menunjukkan bahwa Vietnam adalah bumi kedamaian dan kekeluargaan dengan kehidupan normalnya. Dengan kata lain, himpitan ekonomi yang dia alami di Amerika karena terpinggirnya dia sebagi etnis minoritas membuatnya sampai pada kesadaran siapa jati dirinya. Bahwa Amerika bukanlah negara yang tepat bagi dia, dan keluarganya, untuk dijadikan tempat melangsungkan kehidupannya. Beban psikologis dan ekonomi yang dia dan keluarganya sandang karena jenis pekerjaan yang mereka lakukan membuat mereka membangun mimpi mereka untuk pulang dalam kehidupan baru mereka di Vietnam, sebagimana halnya kedua orang tua lê yang akhirnya pulang ke tanah leluhur untuk menghabiskan sisa waktu hidup mereka.

\section{SIMPULAN}

Sesuai dengan fokus penelitian dan hasil pembahasan yang telah dilakukan, dapat disimpulkan bahwa penyair dari keempat puisi yang menjadi subyek bahasan penelitian ini mengalami represi dalam aspek sosio-budaya, politik, dan ekonomi kehidupan mereka sebagai akibat dari terpinggirkanya mereka sebagai etnis minoritas seperti yang disuarakan oleh masing-masing persona cipitaan penyair tersebut.

Julia Alvarez mengalami represi sosio-budaya karena penggunaan bahasa dalam berkomunikasi sehari-hari. Alva- 
rez yang berbahasa ibu bahasa Spanyol diharuskan menggunakan bahasa Inggris. Meskipun dia mampu melakukan komunikasi, dia sering kesulitan untuk mengungkapkan apa yang sebenarnya dia maksudkan karena bahasa juga menyangkut masalah budaya. Karena masalah bahasa pula, dia terrepresi secara sosial oleh masyarakat dari etnis mayoritas. Resistensi yang dia lakukan atas represi ini adalah tetap memelihara bahasa ibu yang dia miliki yang menurut dia lebih unggul karena efektifitas, ketepatan makna, kedekatan, dan kenyaman yang dia rasakan. Dengan kata lain, dia lebih mempunyai kedekatan emosi dengan bahasa ibunya. Akibat dari represi yang dia terima, Alvarez akhirnya sadar akan jati dirinya dengan tetap menghidupkan bahasa ibu yang dia miliki sebagaimana nampak pada puisi yang menjadi subyek penelitian ini.

Naomi Shihab Nye mengalami represi politik dalam bentuk sentiment etnis. Mula-mula represi ini hanya menyangkut masalah dia pribadi dan keluarganya, namun kemudian melebar menjadi masalah publik yang menyangkut bangsa Arab. Akibat represi ini, dia justru menemukan bahwa ras Arab yang mengalir dalam dirinya mempunyai keunggulan-keunggulan yang lebih dalam hal relijiusitas, keberadaban, dan kearifan lokal. Kesadaran ini membawa dia untuk mengambil sikap dengan membela rasnya yang diperlakukan dengan semena-mena oleh etnis mayoritas yang menjadi tulang punggung bangsa Amerika. Dia pun melakukan protes kerasnya. Dia telah menemukan jati dirinya.

Rhina P. Espaillat mengalami represi sosial dalam hal penggunaan bahasa yang justru datang dari pihak keluarganya sendiri. Ayahnya melarang Espaillat menggunakan bahasa Inggris dalam lingkungan keluarga. Dia harus menggunkan bahasa Spanyol. Represi ini menjadi sulit untuk dia terima karena Espaillat tidak ingin memisahkan penggunaan kedua bahasa tersebut dalam kehidupannya. Resistensi yang dia lakukan adalah dengan cara menolak pembatasan ini dan, secara diam-diam, dia terus mempelajari bahasa Inggris karena kesadarannya bahwa dia sekarang tinggal di negara yang menggunakan bahasa Inggris sebagai alat komunikasi utamanya. Dengan melakukan hal ini, akhirnya dia sampai pada jati dirinya, yaitu hidup dengan dua bahasa dan dua budaya yang berbeda, seperti bahasa yang dia gunakan dalam puisinya.

lê thị diễm thúy mengalami represi dalam bidang ekonomi. lê yang merupakan pengungsi akibat Perang Vietnam ini tidak mendapatkan kesejahteraan ekonomi yang memadai karena jenis pekerjaan yang terpaksa dilakukan ayahnya. Secara implisit jelas bahwa apa yang dia alami merupakan akibat dari posisinya sebagai etnis minoritas. Beban berat dalam aspek ekonomi, dan yang berakibat pula pada aspek sosial kehidupannya ini, dia lawan dengan protesnya yang mengatakan bahwa Vietnam bukanlah medan perang. Terjadinya perang di negara ini karena ulah Amerika. Dia yakin bahwa dia bisa mendapatkan kedamaian, rasa persaudaraan dan kekeluargaan, cinta, dan 'dunia' yang dia impikan di Vietnam. Resistensi yang dia lakukan yang merupakan akibat represi yang dia alami ini akhirnya membawa pada kesadaran jati dirinya. Bahwa Amerika bukanlah tem- 
pat yang dia harapkan untuk dapat melangsungkan kehidupannya. Dia ingin membangun dunia barunya dengan pulang kembali ke Vietnam.

\section{UCAPAN TERIMA KASIH}

Artikel ini merupakan bagian dari penelitian yang berjudul "Diaspora Etnik Non Anglo-Saxon dalam Kungkungan Sosial Budaya Masyarakat Etnik Ango-Anglo-Saxon: Kegetiran dan Keterasingan dalam Realita Hidup", yang didanai oleh BOPTN FBS UNY. Ucapan terima kasih disampaikan kepada Dekan dan BPP FBS UNY, reviewer, dan redaksi yang telah memfasilitasi penelitian dan artikel ini.

\section{DAFTAR PUSTAKA}

Andoni, H., Agus S., Ekomadyo. 2016. "Interpretasi Identitas Budaya Diaspora Masyarakat Minangkabau: Sebuah Kajian Semiotika pada Rumah Makan Padang di Bandung". Seminar Nasional - Semesta Aristektur Nusantara 4. Malang: Universitas Brawijaya Malang.

Ashcroft, B., Gareth G., \& Helen T. 1998. Key Concepts in Post-Colonial Studies. London \& New York: Routledge.

Green. H. M. 1930. An Outline of Australian Literature. Sydney: Whitcombe \& Tombs, Ltd.

Jand, FE. 2004. An Introduction to Intercultural Communication. California: Sage Publication.

Kendzior, S. 2016. How Do You Become 'White' in America? < https:// thecorrespondent.com/5185/howdo-you-become-white-in-> . Diakses tanggal 27 Juli 2018.

Rudjito DA, E. 2010. White Anglo-Saxon Protestan dan Identitas Amerika.
Yogyakarta: staff.uny.ac.id. Diunduh Agustus 2018.

Ryan, M. 1999. Literary Theory: A Practical Introduction. Oxford: Blackwell Publishers Inc.

Ryan, M. 2011. Teori Sastra: Sebuah Pengantar Praktis. Terjemahan oleh Bethari Anissa Ismayasari. Yogyakarta: Jalasutra.

Skerrett Jr., JT. 2002. Literature, Race, and Ethnicity. Addison: Wesley Longman Inc.

\section{SUMBER DATA}

English Literature. <en.wikipedia.org/ wiki/English_literature>. Diakses tanggal 7 Juli 2014.

Intro to Poetry: Bilingual/Bilingue. $<$ https://afraguas.wordpress. com/2011/08/07/bilingualbilingue $>$. Diakses tanggal 30 Juli 2018.

Julia Alvarez. <https://en.wikipedia. org/wiki/Julia_Alvarez>. Diakses tanggal 4 Agustus 2018.

Julia Alvarez Biography. <http://www. notablebiographies.com/A-An/Alvarez-Julia.html>. Diakses tanggal 27 Juli 2018.

lê thi diễm thúy. <https://en.wikipedia. org/wiki/Le_Thi_Diem_Thuy>. Diakses tanggal 6 Agustus 2018.

Major: English Literature. <www. princetonreview.com/Major. aspx?cip $=230801>$. Diakses tanggal 7 Juli 2014.

Naomi Shihab Nye. <https://www. poetryfoundation.org/poets/naomi-shihab-nye $>$. Diakses tanggal 4 Agustus 2018.

Palestinian-American Poet Bridges Two Cultures. 2011. <https:// www.voanews.com/a/palestinian- 
ameican-poet-bridges-2-cultures $>$. Diakses tanggal 31 Juli 2018.

Rhina P. Espaillat. < https://www.poetryfoundation.org/poets/rhine-pespaillat $>$. Diakses tanggal 3 Agustus 2018.
RhinaEspaillat. < https://en.wikipedia. org/wiki/Rhina_Espaillat>. Diakses tanggal 27 Juli 2018. 